\title{
Effects of leptin on histomorphometry of liver in high-fat diet fed obese rats
}

\author{
Elfide Gizem Kıvrak, Işınsu Aydın, Gamze Tümentemur, B. Zuhal Altunkaynak*, Süleyman Kaplan
}

${ }^{a}$ Department of Histology and Embryology, Faculty of Medicine, Ondokuz Mayis University, Samsun, Turkey

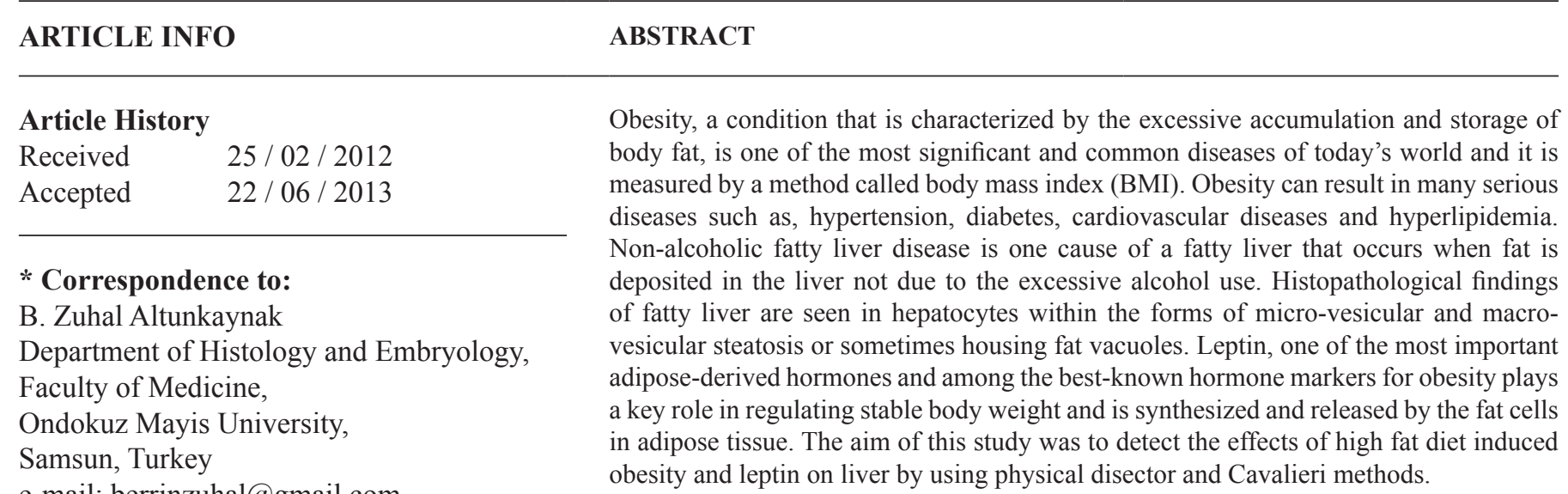

e-mail: berrinzuhal@gmail.com

Keywords:

High fat diet

Leptin

Non-alcoholic fatty liver disease

(C) 2013 OMU

Obesity

Rat

\section{Introduction}

Obesity is a condition characterized by the excessive accumulation and storage of body fat and it is one of the most significant and common diseases of today's world (Yavuz and Tontuş, 2013). It occurs when there is an increase of the accumulation of body fat when compared to the height of an individual and it is measured with a method called body mass index (BMI) (Üstün and Köksal, 2013). People whose BMI is over 30 are considered as obese. Obesity can result in many serious potentially life threatening diseases such as, hypertension, diabetes, cardiovascular diseases and hyperlipidemia (Altunkaynak and Özbek, 2009).

The increase of excessive fat on one's body can result with the deposit fat around the organs (Kiki et al., 2007). Non-alcoholic fatty liver disease (NAFLD) is one cause of a fatty liver that occurs when fat is deposited in the liver not due to the excessive alcohol use. Within itself this definition is divided into two aspects; 1 . Non-alcoholic steatosis: When there is fat deposited around the liver without inflammation. 2. Non-alcoholic steatohepatitis: It is seen with the occurrence of fatty liver and just like it is observed in alcoholic liver cases, balloons in hepatocytes, inflammatory infiltra- tion, Mallory corpuscles, mega mitochondria and fibrosis findings may occur (Sonsuz, 2007). Histopathological findings of fatty liver are seen in hepatocytes within the forms of micro-vesicular and macro-vesicular steatosis or sometimes housing both fat vacuoles (Sonsuz, 2007).

Leptin, one of the most important adipose-derived hormones and among the best-known hormone markers for obesity was discovered in 1994 by Fiedman and his colleagues (Büyükokuroğlu et al., 1999). Leptin plays a key role in regulating stable body weight and is synthesized and released by the fat cells in adipose tissue (Hekimoğlu, 2006). Increased fat mass increases leptin levels in bloodstream which then controls the need of food consumption and reduces body weight and on the contrary decreased fat mass leads to a decrease in leptin levels and an increase in body weight. It also plays a role in regulating metabolism, sexual development and reproduction (Hekimoğlu, 2006). Individuals who are slim have higher levels of leptin than individuals who are obese (Büyükokuroğlu et al., 1999). Leptin receptors are housed both in brain and peripheral tissues and therefore it plays a part in controlling the alimentation, thermogenesis, immune system, reproduction, bone density, development of 
brain, hemodynamics, respiratory, sympathetic nerve activity, and regulates the insulin levels in liver (Hekimoğlu, 2006).

Stereology is a field of science which provides meaningful quantitative descriptions of the geometry of threedimensional (3D) structures from measurements that are made on two-dimensional (2D) images. The specialization of stereological tools makes these estimates unbiased and reliable. Stereological methods utilize various specific tools and sampling strategies to provide unbiased and quantitative estimates in order to obtain a wide range of quantitative parameters including the number, size, shape, volume and density (Altunkaynak et al., 2012).

In this study, we aimed to detect effects of high fat diet induced obesity and leptin on liver by using physical disector and Cavalieri methods.

\section{Material and methods}

The environment of the study and selection of test subjects

Twenty-four adult female Wistar Albino rats (180-210 gr each) obtained from the Experimental Research and Application Center of Ondokuz Mayis University and they were randomly allocated to four groups. The rats were housed in plastic cages ( 2 animals per cage), maintained under standardized conditions of light (12-h light/dark cycle) and room temperature $\left(22 \pm 2^{\circ} \mathrm{C}\right)$, with free access to food and tap water. The diet consumption of all animals was monitored daily, and the animals were weighed once every day so as to detect any weight increase.

\section{The procedure of the experiment}

The 24 rats used in this study were randomly divided into 4 groups including non-obese control (NC group), obese control (OC group), non-obese leptin (NOL group) and obeseleptin (OL group) groups. In obese groups, rats were fed with high fat diet (40\% calories from fat) during 15 weeks and at the end of this period; whether the subjects became obese or not was tested by their BMI values (Altunkaynak et al., 2009). Rats of the non-obese groups were fed with standard, commercial rat diet during the same time. At the end of the feeding period, rats in the leptin groups were subjected into $1 \mu \mathrm{g} / \mathrm{kg}$ i.p leptin treatment for 42 days by utilizing the own diets.

Preparation of leptin solution: Mouse recombinant leptin (Sigma $1 \mathrm{~L}-3772-O B$ ) was added in $100 \mathrm{ml}$ saline by vortexing and the solution was stored at $+4 \mathrm{C}$. Leptin solutions were freshly prepared in sterile conditions and injected after calculatine the concentration of leptin for each rat $(1 \mu \mathrm{g} / \mathrm{kg}$ body weight/day). Injections were made intraperitoneally at the same hour of the day (16.00-17.00) for 42 days.

\section{Histological procedure}

The animals were anesthetized and their BMI was calculated. Subsequently, the anesthetized animals were sacrificed by intra-cardiac perfusion of $10 \%$ formalin solution. Then, whole livers were removed from the rats and processed for stereological and light microscopical analyses.

The removed fresh livers were firstly immersed in water and were measured. For stereological methods; livers were systematically and randomly sampled using fractionating knives. Subsequently, selected liver cubes were post-fixed in
$10 \%$ formalin solution and dehydrated in graded alcohol series, embedded in paraffin wax, and serially sectioned using microtome (Leica ${ }^{\circledR}$; Germany). Selected sections according to unbiased sampling interval were stained with hematoxylineosin.

\section{Stereological methods}

The volume of liver (LV) was estimated using the Cavalieri principle. Thus, two different point counting grids were used to estimate the volumes of sinusoids and liver. The total number of hepatocyctes was calculated using the physical disector method.

\section{Volume estimation by the Cavalieri principle}

Volume estimation of a structure that has an arbitrary shape and size may be efficiently obtained by the Cavalieri principle. An important rule of this principle is as follows: in order to get an unbiased estimation of the volume of an object, the object must be cut to serial and parallel planes separated by a fixed distance and using a point-counting grid for the area estimation of section profiles (Kalaycığlu et al., 2013). The test grid with a systematic array of points is randomly placed on the screen of a PC and an appropriate point per interested area carefully calculated for each section.

In this study, stereological analyses were made on microscopical views of the liver samples. The volume of surface of interest in all liver section was estimated using the following formula:

\section{Volume: $\mathbf{t} \times \mathbf{a} / \mathbf{p} \times \sum \mathbf{P}$}

Where, "t", is section thickness; " $a / p$ ", is representing the area of each point on the pointcounting grid; " $\sum \mathrm{P}$ ", is total number of the points hitting the area of interest. (Altunkaynak and Özbek, 2009). Then, the total volume of sampled sections from all rat liver was multiplied by 1400 (section sampling fraction) to estimate liver volume.

\section{Estimation of hepatocytes number}

The sampling of physical dissector pairs was done as described previously. In brief, the all liver was obtained about 180 parts. According to our preliminary study, the pairs from every 9th section were chosen randomly, and in this way approximately 15-20 section pairs were obtained. It has been reported that this number is in an acceptable range for stereological analysis. Dissector pairs were taken from the tissue at a known interval, until the tissue sample was exhausted. Two consecutive sections were mounted on each slide. Photographs of adjacent sections were taken with an invert microscope (Leica ${ }^{\circledR}$ DFC295; Germany) at a magnification of $x$ 400. If a nucleolus of the hepatocytes is seen in the reference section but not in the look-up section it is counted as a dissector particle. To increase the countable dissector particle number, i.e. nucleolus, the role of the second sections step is changed. An unbiased counting frame was placed on the reference and the look-up sections on the screen of the PC to perform the counting according to the dissector counting method.

The mean numerical density of hepatocytes $(\mathrm{NV}(\mathrm{HC}))$ in per $\mathrm{mm}^{3}$ was estimated using the following formula.

$$
\mathbf{N v}(\mathrm{HC})=\sum \mathbf{Q}-(\mathbf{H C}) / \mathbf{t} \cdot \mathbf{a f}
$$


Where $\Sigma Q_{(\mathrm{hc})}$ is the total number of nucleus seen in the reference but in the look up section; $t$ is the mean section thickness $(1 \mu \mathrm{m})$ and $a f$ is the area of unbiased counting frame.

Histopathological examinations were carried out on the images of the same sections at light microscopical level.

Stereoinvestigator: The stereological analysis was made with the physical fractionator and Cavalieri method, using a workstation made with a microscope (Leica ${ }^{\circledR}$; Germany) equipped with a matching condenser, to control the movements in z-axis (accuracy $0.5 \mu \mathrm{m}$ ), a motorized stage for stepwise displacement in $\mathrm{x}-\mathrm{y}$ axis (accuracy $1 \mu \mathrm{m}$ ), and a CCD video camera (MBF Bioscience; USA) connected to a 17 inch. PC monitor (Acer; Türkiye). The whole system was controlled by the software stereoinvestigator (MicroBrightField Inc., Wiliston,Vt., USA; version 9.0) (Vamecq et al., 1993; Aguila et al., 2003, Gilat et al., 2003; Şahin et al., 2003; Nicol et al., 2005).

\section{Statistical analyses}

Microsoft ${ }^{\circledR}$ SPSS Version 15.0 for Windows was used for statistical analyses. One-way ANOVA with Bonferroni Post Hoc Test was applied to compare volumes of the liver, sinusoids and also mean numerical density of hepatocytes among the all groups with each other.

\section{Results}

\section{Volumetric results}

Firstly, volumes of liver were estimated using the water immersion method. Volumes of all liver sections and sinusoids were estimated by Cavalieri principle.

Liver volumes of control and obese groups were significantly different from each other. But, there was not any significant difference between LVs of control and the OL group and also between LVs of NOL and OL groups.

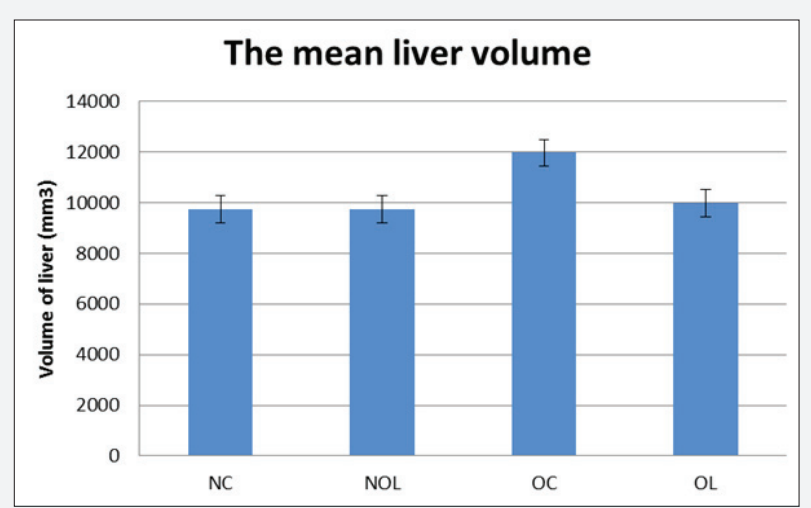

Fig. 1. The volume of liver of the animals from the obese and the control groups. (NC: non-obese control group; OC: obese control group; NOL: non-obese leptin group; OL: obese leptin group)

\section{Mean numerical density of hepatocytes:}

The mean numerical densities of hepatocytes in the OC, the the NC, the NOL, and the OL, were shown in Fig. 2. The numerical densities of hepatocytes for both the obese-control were significantly decreased in comparison to the control group. The mean numerical density of hepatocytes for the obese group were significantly decreased in comparison to the control group (Fig. 2). But leptin application lead to a significant increase of hepatocyte number in OL group after fatty diet induced obesity.

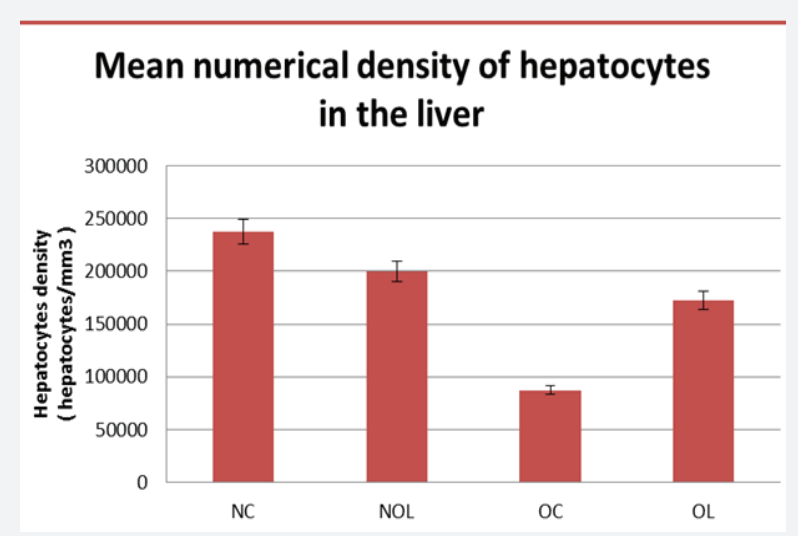

Fig. 2. The mean numerical density of hepatocytes of the animals from the obese and the control groups. ( $\mathrm{NC}$ : nonobese control group; OC: obese control group; NOL: non-obese leptin group; OL: obese leptin group)

\section{Histological results}

In NC and NOL group, livers have healthy histological structure and also hepatocyte cords, central veins and portal triads had normal appearance (Fig. 3A, B). But, in livers of OC group, steatosis, ballooning degeneration and many hypertrophied cells were found (Fig. 3C, circle). Also between hepatocyte plates possible dead hepatocytes with small dark cytoplasm and pycnotic nuclei were seen (Fig. 3C, arrows). In sinusoids fibrin deposits were detected (Fig. 3C, asterisks). In leptin treated obese rats, steatosis was decreased and any hypertrophic cell or possible dead cells were not observed. Moreover sinusoids didn't include any deposits (Fig. 3D).

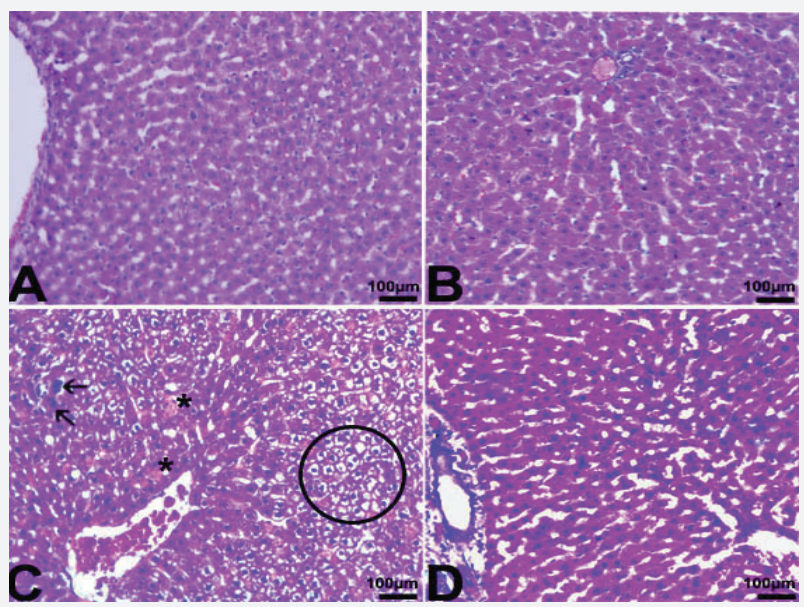

Fig. 3. Light microscopical images of livers from NC, OC, NOL and OL groups. A: Healthy histological structure and hepatocyte cord, central veins and portal triad of the control livers. B: Healthy histological structure and a hepatocyte cord, central vein and portal triad of the non-obese leptin group. C. Histological structure of obese control group. Circle shows steatosis, ballooning degeneration and many hypertrophied cells. Arrows show dead hepatocytes with small dark cytoplasm and pycnotic nuclei. Asterisks show fibrin deposits in the sinusoids. D: Healthier histological structure and hepatocyte cord, central vein and portal triad of the obese leptin group than obese ones. 


\section{Discussion}

Stereological procedures are efficient methods, if you want to get quantitative analyses, interesting volume of objects in any biological tissue or organ. This methods were used in our study involves a hierarchy of systematic random sampling combined with the Cavalieri method.

Fatty liver (hepatosteatosis) is described as to contain fat at least $5 \%$ more of its own weight of the liver or is histologically also described, determination of fat vacuolesinmore than $5 \%$ of hepatocytes. NAFLD is a liver damage, in individuals without alcohol consumption. It is dominated by macrovesicularsteatosis. The prevalence of NAFLD in western countries is estimated to be $20 \%-30 \%$. Current guidelines recommended liver biopsy for diagnosis that is the "gold standard" for quantification of hepatic steatosis associated with NAFLD (Cacciapuoti et al., 2013).

However, it is hard to be accepted due to its invasiveness and a significant degree of sampling error. In addition, it is invasive, costly and prone to complications (Cacciapuoti et al., 2013). NAFLD is containing a large scale table in people who doesn't have alcohol consumption harmful for liver. There is benign clinic course only in fatty liver diseases. Recent reports have confirmed that chronic hepatitis or fibrosis is observed only in fatty liver diseases (Erkal, 2008). Fatty-diet is a factor not only in obesity but also in occurring many different diseases, insulin resistance and NAFLD, characterized with hepatomegaly.

Leptin that is synthetized by ob gene in human adipose tissue is collaborated appetency and consuming energy. The expiration of leptin which contains 167 amino acids is shown in primary white adipose tissue, vascular tissue and liver. Leptin has a great role in regulation of metabolism and has multiple neuroendocrine functions (adeno-neurohypophysis and hypothalamus-hypophysis tract). Leptin shows adaptive regulations in favor of protecting fat reserves. It has also shown that leptin has important role in most of the physiological processes including lipid metabolism, angiogenesis, reproductive system (İşbilen et al., 2007). İşbilen at al. (2007) has shown that there is an increase in high-fat diet, serum and LV leptin levels. It has shown that serum leptin level is remarkable high in obese people. Fat supplement is shown in rats that has $\mathrm{Ob}$ gene defect (ob/ob type) because of the inefficient syntheses of the leptin hormone. It has shown a positive correlation between body mass index and leptin level in obese men and obese women. Leptin level decreases in 24 hours of starvation at $30 \%$ rates and increases in over-nutrition at $50 \%$ rates. Changes in mass of adipose tissue closely effects to leptin levels. It has shown by Condsidine and friends that loss of weight in $10 \%$ rates cause decreases in leptin level at $53 \%$ rates, during the 4 weeks period that there is not loose of weight, leptin is increases and it reaches to the $70 \%$ of the beginning level. Loss of weight gives rise to decreasedleptin level (Gültürk and İmir, 2006).

In our study, we investigated the histopathological effects of fatty diet performed $(\% 40)$ obesity and leptinon female rat livers.

Our volumetric analyses were made by Cavalieri method and our findings showed that; LVs significantly increased in obese animals, but this increase was minimal and wasn't significant inleptin given obese animals. In an experimental study published by Halaas et al., five $\mu \mathrm{g} / \mathrm{kg}$ leptinintraperitoneally was administered to rats. They found $40 \%$ of weight loss and expected that liver volume was to be closed to normal volumetric values. They thought that his result was due to fatty acid oxidation (Halaas et al., 1995).

At another study, number of hepatocytes was observed and it was significantly lower in obese rats than those of the non-obese ones Altunkaynak and Özbek(2009). However, the mean numerical density of binuclear hepatocytes significantly (approximately 38.33\%) increased in obese rats compared with the control group (Altunkaynak and Özbek, 2009).In our study, the number of hepatocytes significantly decreased in obese control group. In leptin administered group, we observed approaching values of hepatocyte number to that of the control group.

According to our light microscopical findings, any signif $\neg$ icant difference wasn't found between NC and NOL group in the light microscopical analysis. The histological structures of livers in both groups were observed as similar. The reason for this might be leptin, because it prevents the accumulation of lipids in the cells. As Auwerx and Steels (1998) have pointed out, it can be due to these reasons; (1) lipid prevents the effect of acetyl coenzyme -A carboxylase which is rate-limiting enzyme of fatty acid synthesis, (2) lipid reduces the synthesis of fatty acids and triglycerides, (3) lipid increases lipid oxidation can show the effects.

In this study we detected important histological differences between OC and NC groups. There were hydropic degenerations and dead cells in OC group signing parenchymal damage. Also steatosis was observed in obese rat livers. Some researchers reported that steatosis was over due to insufficient production of leptin on ob/ob rats, which have ob gene defect (Gültürk and İmir, 2006). Accompanied with this finding, steatosis was not observed in leptin given obese rats as possible result of enough leptin levels in liver parenchyma. Moreover we didn't see any histopathological changes in OL group unlike with those of the OC group. So, this fact can be explained by leptin levels. İşbilen et al. (2007) in their study showed that if serum leptin levels increases in case of obesity, leptin could plays a role in correcting the damage.

Finally, all of the data obtained from our study suggest that leptin has a protective effect on the liver in terms of morphometrical parameters which are liver volumes and numerical density of hepatocytes and histological structure in fatty diet induced obese rat model.

\section{Acknowledgements}

This work was performed by funds from the Ondokuz May1s University (PYO.TIP.1904.11.022).

\section{REFERENCES}

Altunkaynak, B. Z., Özbek, E., 2009. Overweight and structural alterations of the liver in female rats fed a high-fat diet: A stereological and histological study. Turk. J. Gastroenterol. 20, 93-103.

Altunkaynak, B.Z, Onger, M.E., Altunkaynak, M.E., Ayranc1, E., Canan, S., 2012. A brief introduction to stereology and sampling strategies: Basic concepts of stereology. NeuroQuantology. 10, 31-43. 
Auwerx, J., Staels, B., 1998. Leptin. Lancet. 351, 737-742.

Büyükokuroğlu, M. E., Göçer, F., Ünüvar, N., 1999. Leptin. AÜTD. 3, 1-5.

Erkal, T., 2008. Non alkolik yağlı karaciğer yağlı karaciğer hastalığının siroz panelindeki yeri nedir? Uzmanlık tezi. T.C. Sağlik Bakanliği Haseki Eğitim ve Araştirma Hastanesi, İç Hastaliklari kliniği.

Gilat, T., Leikin-Frenkel, A., Goldiner, I., Juhel, C., Lafont, H., Gobbi, D., Konikoff, F.M., 2003. Prevention of diet-induced fatty liver in experimental animals by the oral administration of a fatty acid bile acid conjugate (FABAC). Hepatology; 38, 436-442.

Gültürk, S., İmir, G., 2006. Leptin ve nöroendokrin düzenleme. Journal of Adnan Menderes Universty Medical Faculty. 7, 49-54.

Halaas, J.L., Gajiwala, K.S., Maffei, M., Cohen, S.L., Chait, B.T., Rabinowitz, D., Lallone, R.L., Burley, S.K., Friedman, J.M., 1995. Weightreducing effects of the plasma protein encoded by the obese gene. Science. 269, 543-546.

Hekimoğlu, A., 2006. Leptin ve fizyopatolojik olaylardaki rolü. Dicle Tıp Dergisi. 33, 259-267.

İşbilen, B., Arı, Z., Var. O., Onur, E., Uyanık, B. S., 2007. Yüksek yă̆ içeren diyet ile beslenen ratlarda DHEAS'ın leptin, lipid profili ve endotel fonksiyonu üzerine etkileri. F.Ü. Sağ. Bil. Derg. 21, 109-116.

Kalaycioglu, A., Ucuncu, Y., Altunkaynak, B.Z., Altunkaynak, M.E., Gundogdu, C., Keles,O.N., Unal, B., Kaplan,S., 2013. Stereological evaluation of the kidneys of anencephalic and normal fetuses. Renal Fail. 35, 110-117.

Kiki, I., Altunkaynak, B.Z., Altunkaynak, M.E., Vuraler, O., Unal, D., Kaplan, S., 2007. Effect of high fat diet on the volume of liver and quantitative feature of kupffer cells in the female rat: A stereological and ultrastructural study. Obes. Surg. 17, 1381-1388.

Nicol, C.J., Adachi, M., Akiyama, T.E., Gonzalez, F.J., 2005. PPAR gamma in endothelial cells influences high fat diet-induced hypertension. Am. J. Hypertens. 18, 549-56.

Sahin, B., Emirzeoglu, M., Uzun, A., Incesu, L., Bek, Y., Bilgic, S., Kaplan, S., 2003. Unbiased estimation of the liver volume by the Cavalieri principle using magnetic resonance images. Eur. J. Radiol. 47, 164-170.

Sonsuz, A., 2007. Nonalkolik Karaciğer Yağlanması. İ.Ü. Cerrahpaşa Tıp Fakültesi Sürekli Tıp Eğitimi Etkinlikleri. 58, 91-98.

Turkish Society for Stereology, www.türkstreoloji.org. Accessed: 27.03.2013.

Üstün, Y. B., Köksal, E., 2013. Obezite ve anestezi (J. Exp. Clin. Med., in press).

Vamecq, J., Vallee, L., de la Porte, P.L., Fontaine, M., de Craemer, D., van den Branden, C., Lafont, H., Grataroli, R., Nalbone, G., 1993. Effect of various n-3/n- 6 fatty acid ratio contents of high fat diets on rat liver and heart peroxisomal and mitochondrial beta-oxidation. Biochem. Biophys. Acta. 1170, 151-156.

Yavuz, R., Tontuş, H. Ö., 2013. Erişkin, adolesan ve çocukluk yaş grubunda obeziteye klinik yaklaşım J. Exp. Clin. Med (in press). 